\title{
Designing a Wind Energy Harvester for Connected Vehicles in Green Cities
}

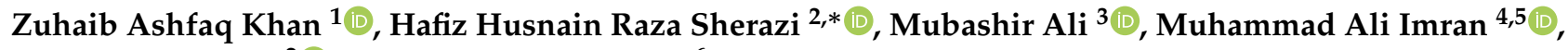 \\ Ikram Ur Rehman ${ }^{2}{ }^{1}$ and Prasun Chakrabarti ${ }^{6}$
}

1 Department of Electrical and Computer Engineering, Attock Campus, COMSATS University Islamabad, Punjab 43600, Pakistan; zuhaibkhan@cuiatk.edu.pk

2 School of Computing and Engineering, University of West London, London W5 5RF, UK; ikram.rehman@uwl.ac.uk

3 Department of Management, Information and Production Engineering, University of Bergamo, 24044 Bergamo, Italy; mubashir.ali@unibg.it

4 School of Engineering, University of Glasgow, Glasgow G12 8QQ, UK; muhammad.imran@glasgow.ac.uk

5 Artificial Intelligence Research Centre (AIRC), Ajman University, Ajman 20550, United Arab Emirates

6 Techno India NJR Institute of Technology, Udaipur, Rajasthan 313003, India; drprasun.cse@gmail.com

* Correspondence: sherazi@uwl.ac.uk

check for updates

Citation: Khan, Z.A.; Sherazi, H.H.R.; Ali, M.; Imran, M.A.; Rehman, I.U.; Chakrabarti, P. Designing a Wind Energy Harvester for Connected Vehicles in Green Cities. Energies 2021, 14, 5408. https://doi.org/10.3390/en14175408

Academic Editor: Dibin Zhu

Received: 7 July 2021

Accepted: 17 August 2021

Published: 31 August 2021

Publisher's Note: MDPI stays neutral with regard to jurisdictional claims in published maps and institutional affiliations.

Copyright: (c) 2021 by the authors. Licensee MDPI, Basel, Switzerland. This article is an open access article distributed under the terms and conditions of the Creative Commons Attribution (CC BY) license (https:/ / creativecommons.org/licenses/by/ $4.0 /)$.
Abstract: Electric vehicles (EVs) have recently gained momentum as an integral part of the Internet of Vehicles (IoV) when authorities started expanding their low emission zones (LEZs) in an effort to build green cities with low carbon footprints. Energy is one of the key requirements of EVs, not only to support the smooth and sustainable operation of EVs, but also to ensure connectivity between the vehicle and the infrastructure in the critical times such as disaster recovery operation. In this context, renewable energy sources (such as wind energy) have an important role to play in the automobile sector towards designing energy-harvesting electric vehicles (EH-EV) to mitigate energy reliance on the national grid. In this article, a novel approach is presented to harness energy from a small-scale wind turbine due to vehicle mobility to support the communication primitives in electric vehicles which enable plenty of IoV use cases. The harvested power is then processed through a regulation circuitry to consequently achieve the desired power supply for the end load (i.e., battery or super capacitor). The suitable orientation for optimum conversion efficiency is proposed through ANSYS-based aerodynamics analysis. The voltage-induced by the DC generator is $35 \mathrm{~V}$ under the no-load condition while it is $25 \mathrm{~V}$ at a rated current of $6.9 \mathrm{~A}$ at full-load, yielding a supply of $100 \mathrm{~W}$ (on constant voltage) at a speed of $90 \mathrm{mph}$ for nominal battery charging.

Keywords: energy harvesting; power management; connected vehicles; wind energy harvester; smart cities; electric vehicle; IoT; Tesla; autonomous sensors

\section{Introduction}

Vehicular ad hoc networks (VANET) [1,2] can genuinely be viewed as a game changer in repainting the future of electric vehicles. The incorporation of the concept of $5 \mathrm{G}$ communication modes is also being widely discussed. These communication paradigms have opened up a broad spectrum of technological advancements such as VANET [3,4], IoV [5-7], and industrial automation [8,9]-to name a few. The IoV promotes connectivity to achieve communication not only among the vehicles, but also with the road side infrastructure that promotes safety and ease of service on the road. This encourages the advancement in IoT, which focuses on the provision of communication services as well as the better control and security of household and commercial areas, paving the way for concepts such as smart cities and smart grids [10]. These practices also lead to new ideas in the field of industrial automation, promoting a new generation of robotics and automated control systems for efficient production. These innovations are going to cause a surge in power consumption in the near future, which requires to explore more ways and methods 
for energy generation. To this end, energy harvesting is a straightforward and elegant approach for powering on-board batteries rather than frequent battery replenishment, in order to maintain a perpetual power supply [11,12].

The constantly increasing carbon emissions caused by conventional gas-powered vehicles have led research efforts towards the inception of electric vehicles (EVs) [13-15], these being one of the greatest inventions of recent decades. This concept started to take form and become implemented during the early 21st century. The practical concept of the electric vehicle was introduced to the world by Tesla Co. The car runs on electric batteries which turn a motor in the car that rotates the axle shaft of the accelerator wheels. The technology has since modernized the automobile industry, but its range and charging are still issues to be revolutionized. The EVs are charged from static charging ports. These charging ports will receive electricity from the power grids which are already responsible for supplying power to different types of loads in residential, commercial, and industrial set ups. The relayance of EVs upon these power stations could cause a huge increase in electricity demand. There is, therefore, a need for a harvesting system for the EVs to reduce their dependence upon power grids-and if the battery is exhausted, there should be a way of feeding the vehicles with energy as it can help in disaster recovery e.g., connected police, fire-brigade and ambulance services can benefit from connectivity while coordinating their responses and services during a disaster.

Several techniques have been introduced for electricity generation in the form of moving vehicles with fans mounted at different positions, i.e., using a windmill mounted on the trunk and the top of a car or a train, however, some serious issues were highlighted as obstacles to efficient and effective generation. Previously proposed approaches were not quite compatible with all types of vehicles as they directly relied on the fan output power. However, there was limited work has been carried out covering the electrical aspects. Quartey et al. [16] first presented the concept for charging a mobile car in which a wind turbine is mounted on the top of the car to charge the car's battery using the wind energy striking on the car. The practical results had drawbacks in terms of the increase in the drag force on the car which affected the efficiency of the car [17]. Then, another work [18] highlighted the cause for the increase in the pressure on the car with the help of simulations. The simulation showed that the front and the bonnet of the car are much more reliable locations for mounting the wind turbine than the top [19].

Another attempt to make a vehicle-mounted wind turbine system was made in [20] where the authors proposed to mount a miniaturized windmill [21] on the back of a pickup truck but the design had a problem as it was not applicable to other types of vehicles [22,23]. Similarly, an energy-harvesting system was presented in [24] which exploits the motion of a moving vehicle's suspension. This system addresses the issues of low energy density, vibration dissipation, and lower energy-harvesting efficiency in current technology. The energy conversion components were introduced with inertial mass and an applied force to establish a dual-mass 2-DOF (degree of freedom) suspension dynamics model. Extending the similar lines, [25] demonstrated that the maximum power harvested by a vehicle suspension system can reach $738 \mathrm{~W}$ and is affected by road roughness.

Moreover, a new dual-mass piezoelectric energy harvester was designed in [26] to collect effective and practical vibration energy from vehicle tires with a maximum power of 42.08 W. Furthermore, [27] proposes an electric vehicle with an energy-harvesting system embracing vibration energy via a shock absorber. Maximum power point tracking algorithms and active output control techniques for active power converters were examined in order to determine how the energy-harvesting technique could be used to enhance the shock absorbers in vehicle suspension. An electric vehicle with a hybrid suspension system was proposed in [28] which caused the rise in EV sales. The concept, design, and idea of the new damper was provided, along with a simulation mainly focusing on the eddy current damper component. According to the authors, multi-mode energy harvesting provides an EV with a promising renewable source to generate surplus energy. 
In this paper, a novel approach is presented to achieve electric generation in EVs by mounting a small-scale wind turbine (shown in Figure 1) on the top of the vehicle that can support a range of communication primitives, enabling access to plenty of applications for the Internet of Vehicles. Electrical energy is then generated by the onboard DC generator. ANSYS-based aerodynamics analysis is used to determine the optimal power generation orientation. With no load, the voltage induced by the DC generator is $35 \mathrm{~V}$, while when it is fully loaded, it produces $25 \mathrm{~V}$ at a rated current of $6.9 \mathrm{~A}$, and generates $100 \mathrm{~W}$ (at constant voltage) at $90 \mathrm{mph}$ for nominal battery charging. This study shows interesting results in terms of newly harvested energy, making it a cost-effective solution for a number of futuristic use cases in EVs.
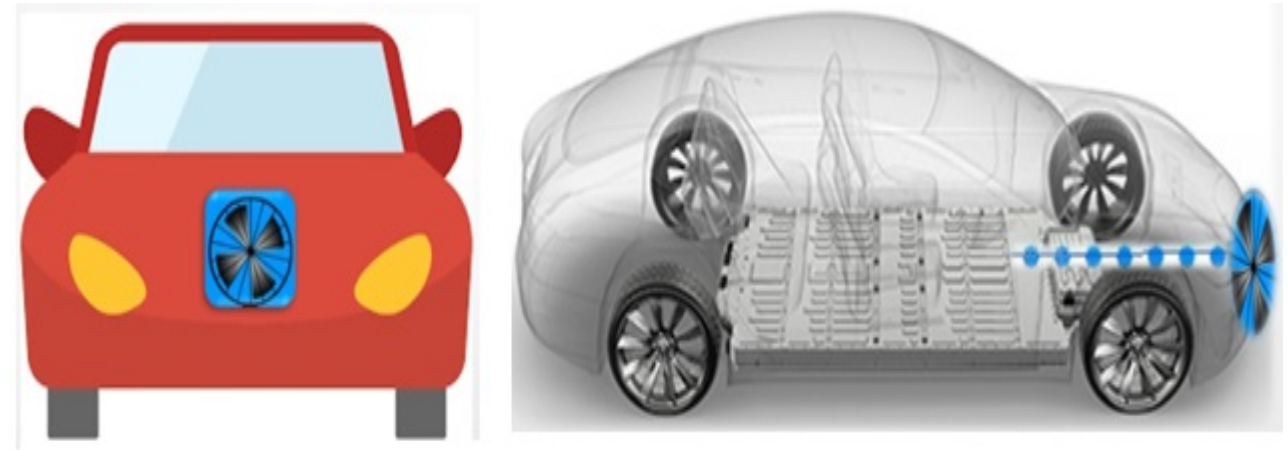

Figure 1. (left) Fan mounted on the front; (right) Side view of electric generation mechanism.

The rest of this work is structured as follows. The overall system design is proposed in Section 2. The complete methodology as well as system operation and monitoring through the Bluetooth module are presented in Section 3. The results and a detailed discussion are provided in Section 4, while Section 5 demonstrates a complete system efficiency analysis. Finally, the concluding remarks are provided in Section 6.

\section{System Model}

A sequential model of the system design is shown in Figure 2 given below. The basic step is the extraction of wind using fan blades, connected with the Permanent Magnet DC (PMDC) motor which generates electricity upon the rotation of its shaft primarily caused by the collision of wind. The motor is connected with a DC regulator which provides a regulated DC output to the battery. This output is measured using the voltage sensor [29] and the current sensor connected with Arduino. There is an LCD screen connected with the Arduino to display the electrical parameters of the regulated output. Then, the next phase is the protection circuitry which has two functions. One is the switching of electric power using a relay module [30] being controlled by Arduino and the decision taken upon the basis of the percentage of the charge ratio of the battery. The other function of protection circuitry is to stop the flow of current from the battery towards the motor by using a power diode [31]. After this, the electrical power is provided to the battery being charged. There is a Bluetooth module connected with Arduino to display the electrical parameters (voltage and current) on the mobile application.

The architecture of the proposed model is demonstrated in Figure 3. The first part of the system is a fan which is being used to convert the energy of the wind into the kinetic energy of the blades. This fan is connected with the shaft of the PMDC motor which, in turn, will rotate it. The DC motor will act as a generator which will generate electricity upon the rotation of its shaft. This generated electricity will be measured by using voltage and current sensors [32] in parallel and series, respectively. The output of the DC motor will be fed to the DC regulator which regulates the generated output voltage. The output of the DC regulator is again measured using voltage and current sensors so as to calculate the voltage and current, respectively, and thus power. In this way, the input and output electrical parameters of the DC regulator are used to measure the efficiency 
of the regulator. After this, there will be a protection circuitry installed which contains a relay module and a diode. Arduino continuously measures the voltage across the battery to calculate the percentage up to which the battery has been charged. Based upon this calculation, the Arduino will decide whether to switch on the relay. If the voltage across the battery is between the minimum and maximum set voltages, the relay will be switched on-otherwise it will be off. From a VANET perspective [33,34], a mobile app operated via a Bluetooth module was also designed, which enabled us to obtain the results of the electric generation on the app for easy access to the data. Finally, the diode before the battery will allow the current to flow only towards it and will stop the current moving in the other direction.

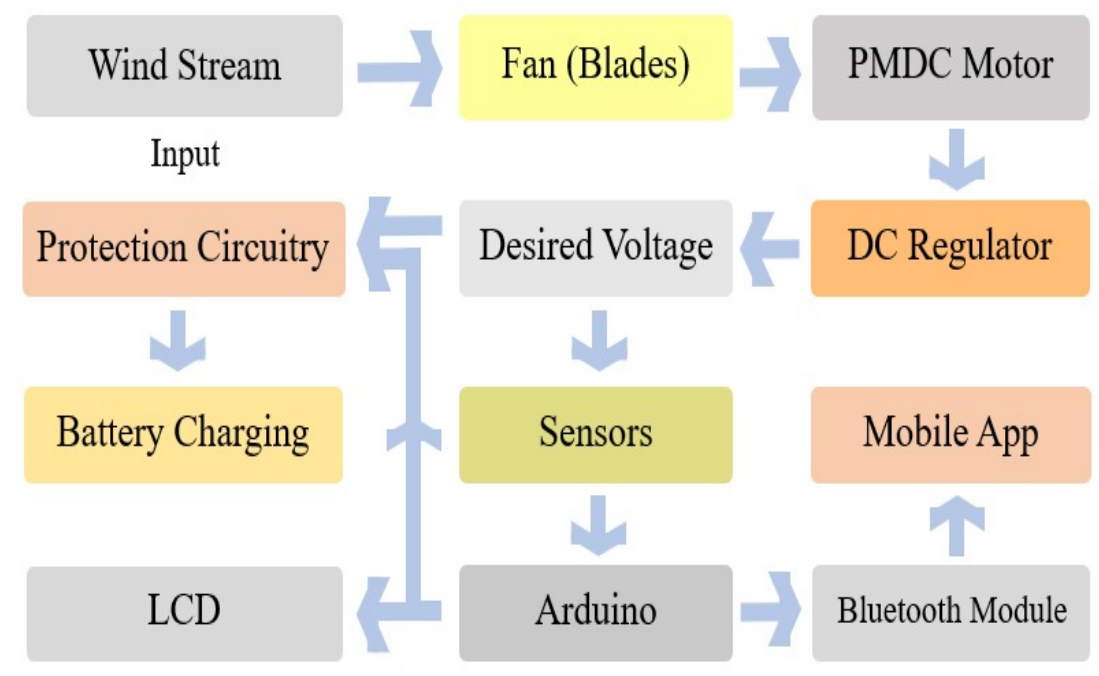

Figure 2. Wind harvesting system block diagram.

\subsection{Mathematical Modeling}

To make a charging system, certain parameters of the car and the electric unit for the production of the charge are required. From the mechanical aspects to the electrical parameters of the car charging system, the complete mathematical modeling of the system is required. The mathematical model of the system can be seen in Figure 4.

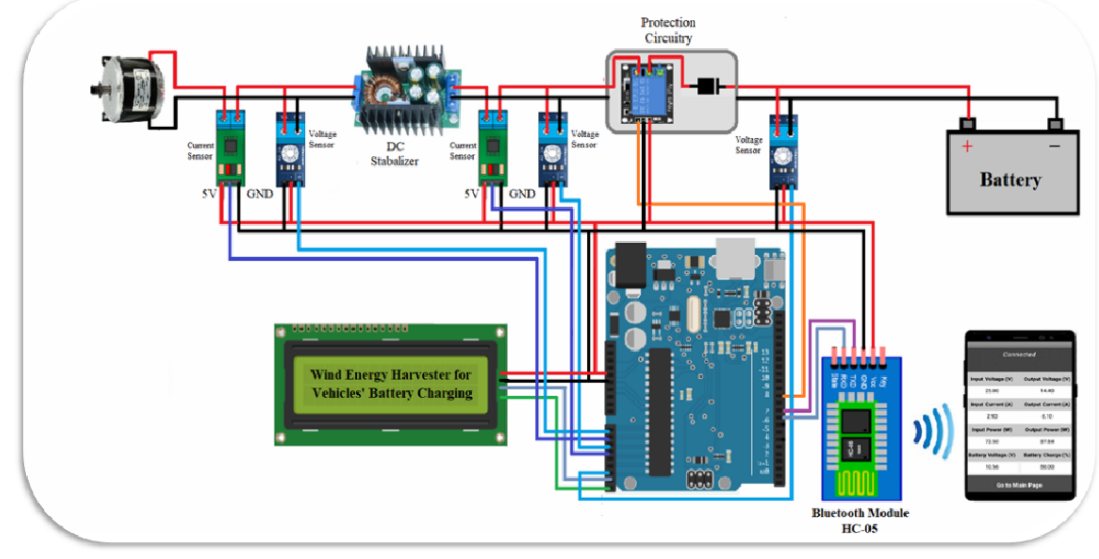

Figure 3. Proposed architecture of the entire harvesting system. 


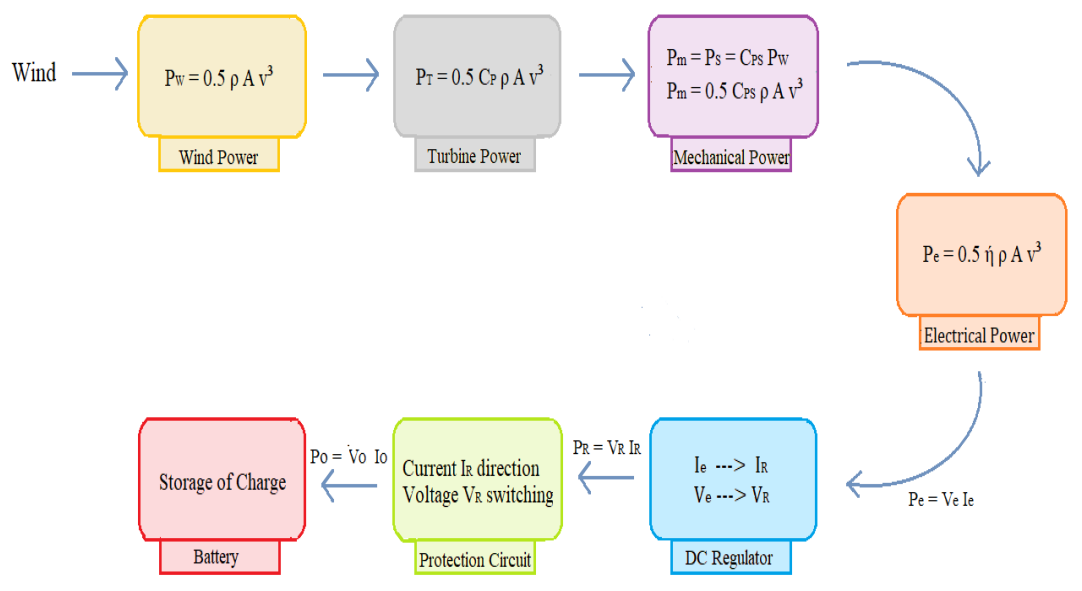

Figure 4. Mathematical model for complete energy conversion cycle.

For the calculation of various stages of power generation, the first key parameter required is the cross-sectional area of the fan, which expresses the wind that will act on this surface for turbine rotation. Under the vehicle's structural limitations, a bigger area means a larger exertion of air pressure. The second one is the air velocity that will be acting on the car due to the change in car speed: a faster car means higher air velocity.

\subsubsection{Wind/Turbine Power}

The air traveling with some velocity will exert kinetic energy on the turbine. Thus, by using Equation (1), the kinetic energy (KE) of the system can be calculated, and now the turbine power generated from air depends upon the mass flow rate of air which is expressed in Equation (2) - where $\rho$ is the density of air, A is the area of the cross-section of turbine, and vs. is the air velocity [35]. Now, the turbine power is equal to the kinetic energy exerted by air given in Equation (3). The formula for the power generated by the turbine via wind power [36] is given in Equation (4), where $P_{r}$ is the turbine power and $C_{P}$ is the power coefficient for the turbine:

$$
\begin{gathered}
K E=\frac{1}{2} \quad m v^{2} \\
m=\rho A v \\
K E=\frac{1}{2} \quad \rho A v^{3} \\
P_{r}=\frac{1}{2} \quad C_{P} \rho A v^{3}
\end{gathered}
$$

\subsubsection{Mechanical Power}

In order to find the shaft power, the first thing we need to determine is the shaft power coefficient. For this, we first need to determine the tip-to-speed ratio of the shaft which is determined by the formula:

$$
\lambda=\frac{4 \pi}{B}
$$

where $B=7$ is the number of blades:

$$
\lambda=\frac{4 \pi}{7}=1.795
$$

$\lambda=1.795$ correlates to a power coefficient $C_{P}=0.13$. 
With an augmentation of $0.2, C_{P_{s}}=0.13+0.21=0.34$, where $C_{P_{s}}$ is the shaft power coefficient. Now, the mechanical power is equal to the shaft power that is:

$$
P_{\text {mech }}=P_{s}=C_{P_{s}} P_{w}=\frac{1}{2} C_{p_{s}} \rho A v^{3}
$$

For the turbine diameter of $0.36 \mathrm{~m}$, the area of the turbine is determined by the formula:

$$
A=\frac{\pi d^{2}}{4}
$$

\subsubsection{Electrical Power}

The shaft power induced in the shaft of the generator is transmitted to the generator for the induction process. This induction is responsible for the generation of electric power. The formula is given in given in Equation (8), where $\eta$ is the net efficiency of the generator. As power in corresponds to (speed and torque) and power out is relative to (speed and current), then the torque mechanical applied is relative to the current being drawn by the windmill. The torque on the rotor can be calculated by the formula of Equation (9), where $\mathrm{T}$ is the torque and $\omega$ is the angular velocity of the rotor. The $\omega$ can be calculated by the formula given in Equation (10), where $\mathrm{R}$ is the length of the fan blade:

$$
\begin{gathered}
P_{\text {elec }}=\frac{1}{2} \eta \rho A v^{3} \\
P_{s}=T \omega \Longrightarrow T=\frac{P_{s}}{\omega} \\
\omega=\frac{\lambda v}{R}
\end{gathered}
$$

\subsubsection{RPMs and Angle of Twist}

The blade angle of the twist is the angle at which blades are set to accumulate the maximum air pressure for effective generation, where $\mathrm{N}$ is the rotational speed of the rotor given in revolutions per minute (rpm) [37], which can be calculated through the formula in Equation (11):

$$
N=\frac{60 \lambda v}{2 \pi R}=\frac{60 \times 1.795 \times 33.33}{2 \times \pi \times 0.18}=3174 \mathrm{rpm} .
$$

\subsubsection{Force Calculation}

The force acting on the fan to operate is the difference between the two forces acting on it. One is the lift force $\left(F_{L}\right)$, exerted by the air to rotate the fan expressed in Equation (12):

$$
F_{L}=\frac{1}{2} C_{L} \rho V^{2} A_{t}
$$

but for every action, an opposite reaction is present. In this case, an opposite force emerges, which tries to restrict the fan from moving. This force is called drag force and is calculated by the following formula in Equation (13):

$$
F_{D}=\frac{1}{2} C_{D} \rho V^{2} A_{t}
$$

where $C_{L}$ and $C_{D}$ are the lift coefficient and drag coefficient, respectively, and $A_{t}$ is the fan surface area. Now, the total force on the fan is the vectorial sum of both forces, meaning that:

$$
F=F_{L} \cos (90-\phi)-F_{D} \sin (90-\phi)
$$




\section{Methodology}

As this research work brought novelty in terms of technology, there was a need to propose its design on the basis of a new analysis to be conducted. Thus, first of all, softwarebased simulations were used to make decisions regarding the hardware of the system. After this, the complete schematic was designed and the hardware was implemented. The components were connected in accordance with the proposed schematic. First of all, the wind turbine, whose output is given to the DC voltage regulator, has the current and voltage sensors on its input and output. The output of the DC voltage regulator is connected to the battery with a protection circuitry in its way. This protection circuitry is used to protect the battery from over-charging and low charging, by switching the circuit $\mathrm{ON}$ and OFF at suitable times. This decision is taken by Arduino. Moreover, this protection circuitry also stops the flow of current back from the battery towards the wind turbine. After this hardware was designed, implemented and tested for its working and it was assured that this hardware is ready to be used practically, it was then implemented on a car.

It can be noticed in Figure 5a that the fan was mounted on the front of the car. Only the fan was out of the car's body, as the air needs to strike the fan to rotate it and no other component, so it is necessary for the fan to be mounted outside the car body. Contrarily, the Permanent Magnet DC (PMDC) Motor was placed inside the car body as there should neither be any type of weight with a fan outside the car nor any drag force due to the placement of the motor. The output of the DC motor was connected to the rest of the circuit using DC wires, suitable for carrying the current through it from inside the car engine. Another view of the fan, mounted outside the car, can be seen in Figure $5 b$.

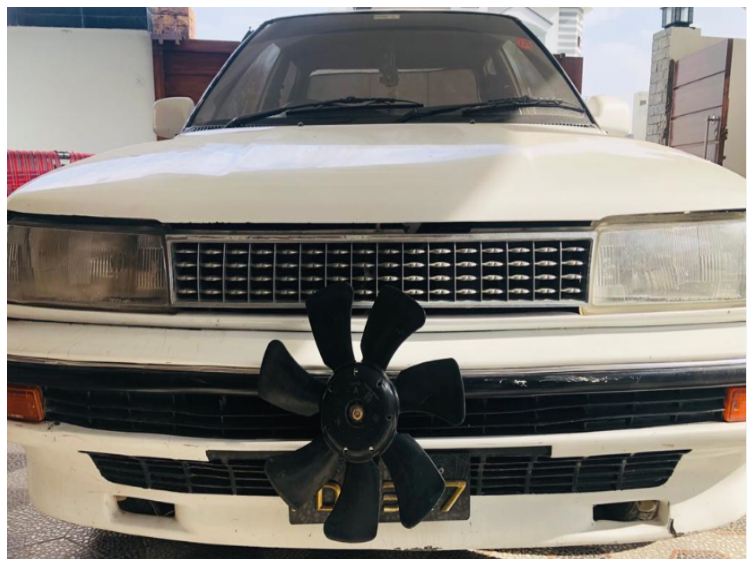

(a)

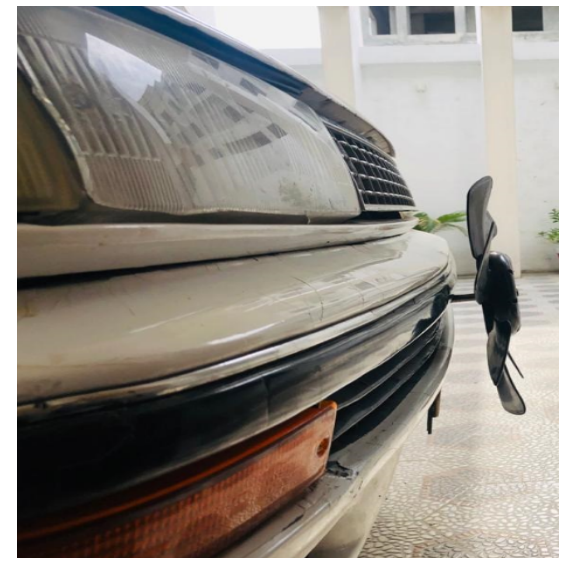

(b)

Figure 5. (a) Front view of a car-mounted fan; (b) Side view of a car-mounted fan.

After the generation of electricity from the wind turbine, the output was supplied to the battery once it was stabilized, measured, and the protection was assured. The DC wires will take this electricity towards the rest of the system, which was placed inside the car. In Figure 6, it is shown that the input is provided to the system for regulation, measurements, and protection work. After this, the output is supplied to the battery so it can be charged:

\subsection{Bluetooth Monitoring via Android App}

In a research study where something is being measured or calculated, there is a need to display it. As in this research article, the data were displayed in LCD using Arduino. Still, there was a need to have a display that was user friendly. Hence, an Android App was developed using the MIT App Inventor, which would display the input and output electrical parameters as well as the battery percentage. These data were sent to a mobile phone from Arduino via Bluetooth connection using a Bluetooth Module, HC-05. This objective of the research was performed after achieving all the milestones of the article and therefore brings this work to two different technologies: 


\subsubsection{Mobile Monitoring}

In this research, the car was driven and a wind turbine was used to generate electricity. This electricity was being measured and displayed on an LCD using Arduino. Furthermore, these data were being sent to the mobile phone of the user to be displayed there in an Android App, as shown in Figure 7. This mobile monitoring was achieved using Bluetooth connection between the Arduino and the mobile phone.

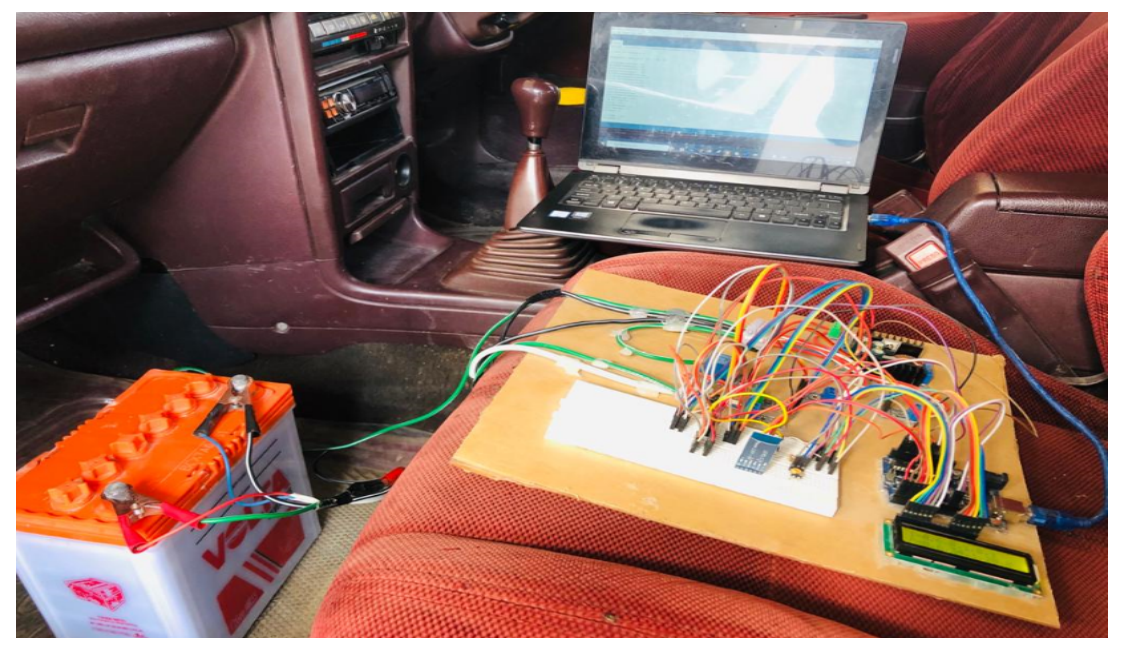

Figure 6. Hardware system implemented in the car.

\subsubsection{Human-Machine Interface}

As the measured data were displayed on the user's mobile phone, it had to be made user-friendly. In this Android App to be installed on the mobile phone of the user, the user will be able to open the introductory part of the app, in which they will be able to see the author's team and also watch the Demo Video of the work. Moreover, the user will be able to connect the mobile to Arduino and start receiving the information from Arduino via Bluetooth.

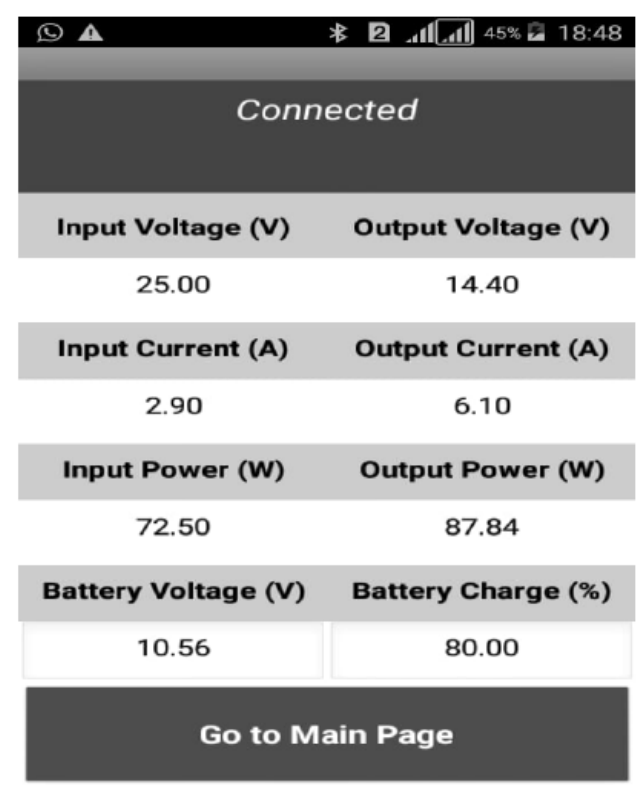

Figure 7. Measurements displayed on the App. 


\section{Results and Discussion}

\subsection{Simulation Results}

For performing the software analysis, the effect of air on the car was simulated by using the ANSYS workspace $16.0[38,39]$ for the evaluation of aerodynamic properties for the execution of our research. Software analysis helped us grasp an idea of the effect of air velocity on the car as well as various zones of drag coefficient present around the vehicle. For the evaluation of the air velocity and drag force, the fluent module of ANSYS was used, in which different analysis techniques were used.

\subsubsection{Iteration Analysis}

In this simulation analysis, the geometry of an EV was included in Fluent to perform some analysis techniques. This simulation was performed for this research work over 200 iterations at a speed of $35 \mathrm{~m} / \mathrm{s}$, which was the maximum speed at which the vehicles were driven in general. In this type of technique, an air thrust was exerted on a car in the entire axis ( $x, y$, and $z$ axis) of the vehicle. The $x$ axis shows the number of iterations and along the $y$ axis shows the scale for the residual air-stream on each coordinate of the vehicle.

\subsubsection{Pathlines Analysis}

This concept was further expanded via running multiple iterations of the same air model using the vectors graphical method. This gave us a comprehensive look at the effect of air on the car. The simulation in Figure 8 shows the regions in which the drag force is strongly present and where its presence is negligible. This indicates that when a car model is designed, priority is given to the aerodynamics of the car for effectively resisting the drag force. Figure 8 also shows how much velocity the air strikes the car with when the car is being driven. It can be seen that there are small lines showing the flow of air towards the car and their color indicates the air velocity in the surroundings of the car. It is clear that there is enough air velocity on the front of the car, which is necessary for the system to work properly. Too much air velocity is not required by the system as there remains a risk of its damage under too much pressure. Thus, the air velocity on the front is sufficient.

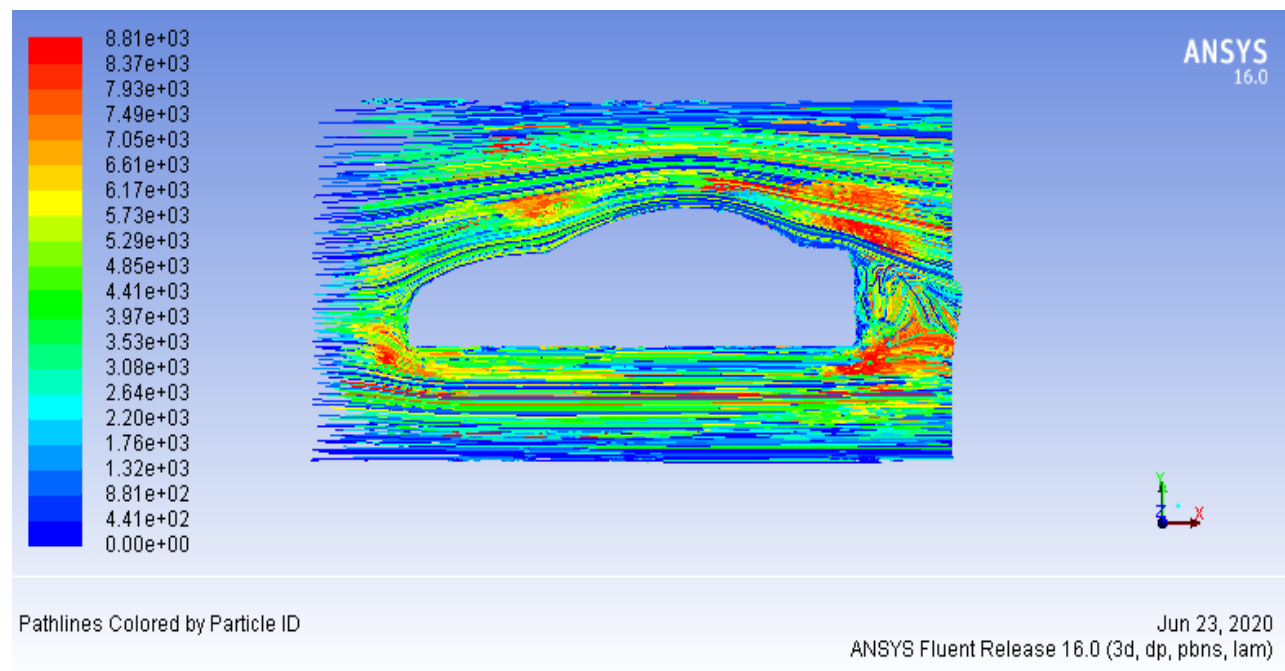

Figure 8. Air flow path-lines.

\subsubsection{Contours Analysis}

The following simulations used contours graphical method which measures the surface area using different iterations, with which complete structural analysis was performed to identify the effect of the air velocity on the vehicle. In Figure 9a, the front as well as sides are easily visible and indicate that the front of the EV directly confronts the maximum air as compared to the other parts of the body, whilst the sides are the second most pressure-tolerant region of the car. Simply, this analysis was performed in function of the 
shape of the car, and shows the parts of the car on which more pressure will be exerted by the wind when the car will be driven. It can be seen that when a car is driven, then due to its direct contact with the wind, there is maximum pressure being exerted. Moreover, the wind screen and other parts also receive a considerable amount of pressure. Another view of the same analysis can be seen in Figure $9 b$, where it is clear that the parts of the car which are vertical in shape receive more pressure from the wind, etc.

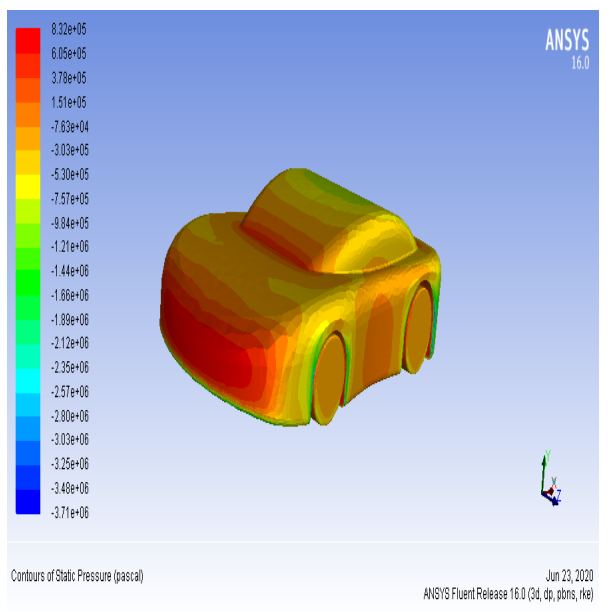

(a)

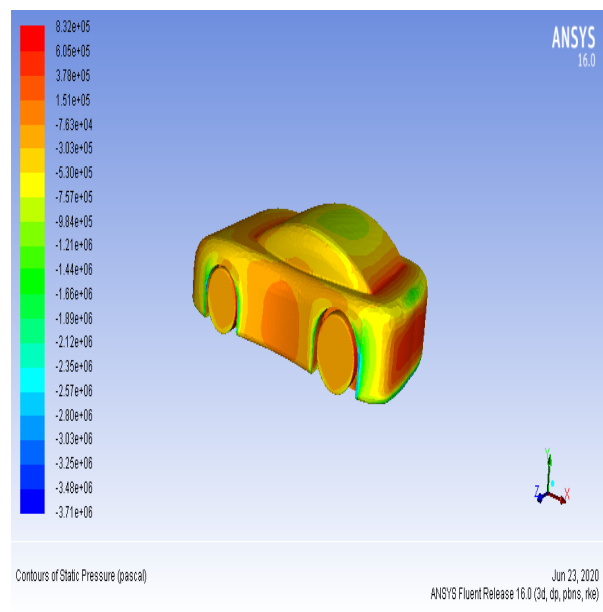

(b)

Figure 9. (a) Contours Analysis with front view; (b) Contours Analysis with side view.

\subsubsection{Velocity Pathway Simulation}

In Figure 10a, the air velocity acting on the car's body is evaluated. It can be seen that most of the air resistance smoothly passes around the car, while the front blocks and directly confronts the air acting on it. As it can be seen, the maximum air velocity is on the top of the car body but this location is not feasible for mounting a diffuser on the roof of the car because this will increase the weight of the vehicle. Thus, keeping this point in mind, a system has been proposed which can be adjusted on the front bumper of the car where the air velocity is according to our system needs. Basically, this analysis also tells us about the drag force on various parts of the vehicle. Now, when this analysis is carried out on a vehicle, it shows that when the air strikes the car, then obviously it has to pass across it in order to keep the vehicle moving. This analysis provides an insight about the air dynamics passing along the vehicle. In Figure 10b, it can be seen that after striking the car, most of the air is moving either from above the car or from beneath it. Hence, there is less drag on the front of the car, as the scale on the left side depicts. Thus, the front of the car is a suitable location for the wind turbine to be mounted. 


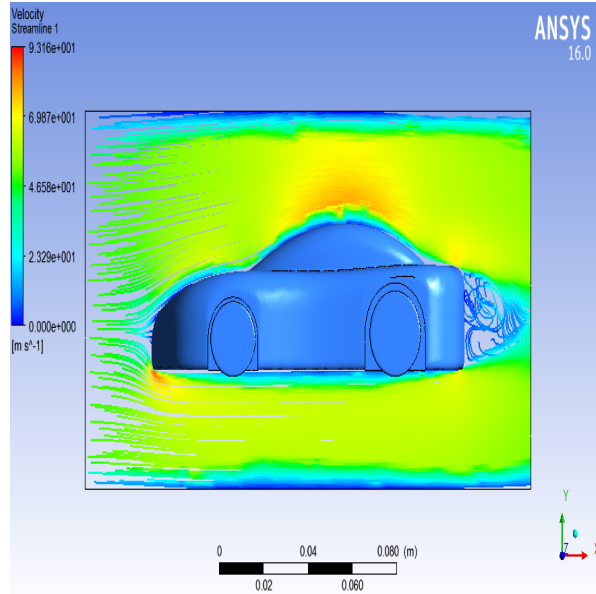

(a)

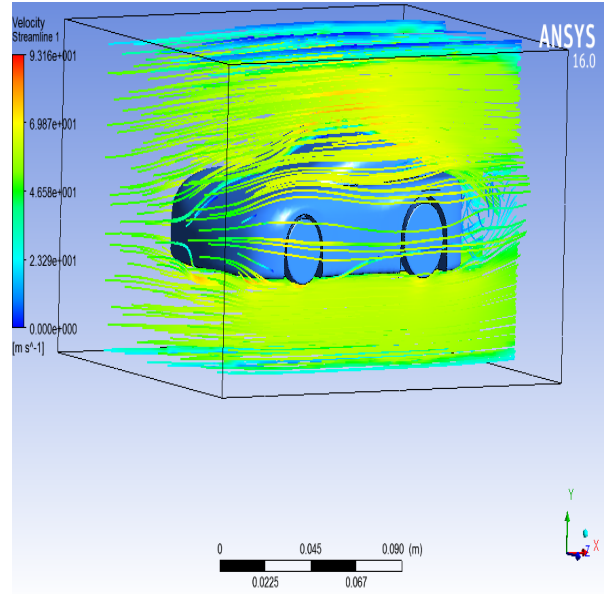

(b)

Figure 10. Air velocity flow analysis in ANSYS with (a) sideways view; (b) 3D view with least drag.

\subsection{Testbed Results}

\subsubsection{Car Speed vs. Air Velocity}

At first, calculations were made on a practical basis to help clarify the difference between the vehicle's velocity and the air velocity on it. This was so that we could clarify the fact that at the designated location, the air velocity was ample enough to run the wind generator's fan blades. The relation between them can be seen in Figure 11, which confirms that the air velocity was slightly less to allow the car to run but had enough kinetic energy to be provided to the generator to generate momentum for the fan blades.

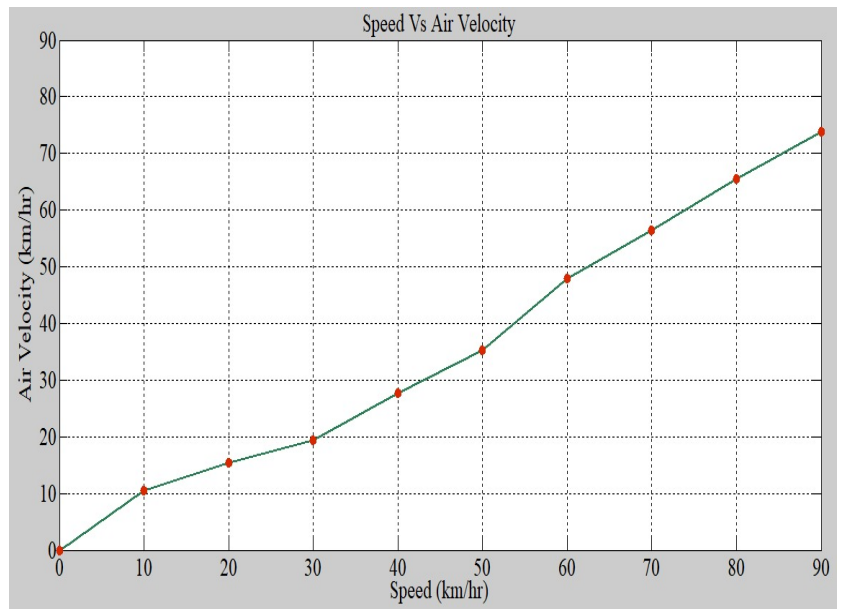

Figure 11. Air velocity against different speeds.

\subsubsection{Car Speed vs. Voltage Generation}

The following graph in Figure 12 was obtained as a result of a comparison between the car speed and the voltages induced in the DC generator with and without load (car battery). It can be observed that the voltage increases with the increase in the car's velocity. Without load, we obtained voltages as high as $35 \mathrm{~V}$ at $90 \mathrm{~km} / \mathrm{h}$, but in the presence of a load, this obtained voltage decreased to approximately $25 \mathrm{~V}$ at the same velocity of $90 \mathrm{~km} / \mathrm{h}$. The regulated line in the given graph indicates the voltages obtained after they passed through a DC regulator to stabilize them at a constant charging voltage, which was $14.6 \mathrm{~V}$ for the lead acid battery - this voltage is achieved at the speed of $45 \mathrm{~km} / \mathrm{h}$. 


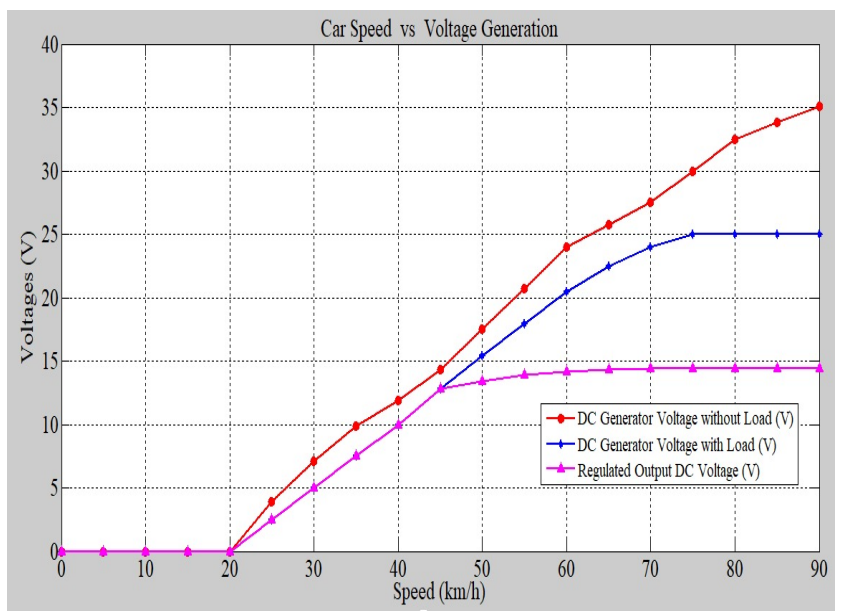

Figure 12. Voltage generation against different speeds.

\subsubsection{Car Speed vs. Electrical Parameters}

On the basis of the data gathered, it can be observed that at $90 \mathrm{~km} / \mathrm{h}$, the generation system has a stable voltage of $14.6 \mathrm{~V}$ with a charging rate of $6.9 \mathrm{Ah}$. The curves indicate that with the increase in the velocity of the car, the voltage and current are also gradually increased, except for the voltage which needs to stabilize after the required charging potential is achieved, as shown in Figure 13. At the speed of $90 \mathrm{~km} / \mathrm{h}$, the total power output obtained is approximately $100 \mathrm{~W}$, as shown in Figure 14 . Here, it can be noted that the charging rate can be increased with some adjustments, but it will jeopardize the life span of the battery.

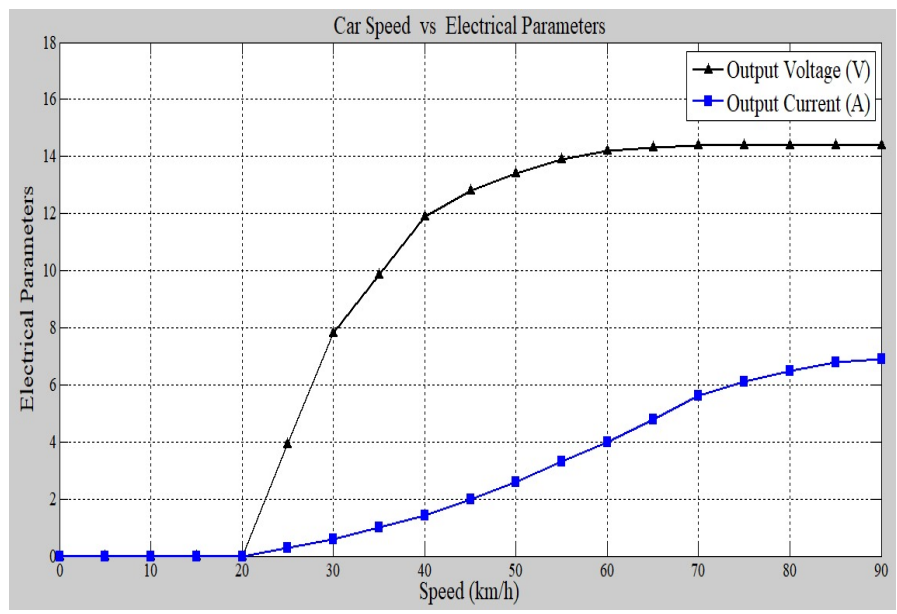

Figure 13. Electrical voltage and current output against different speeds. 


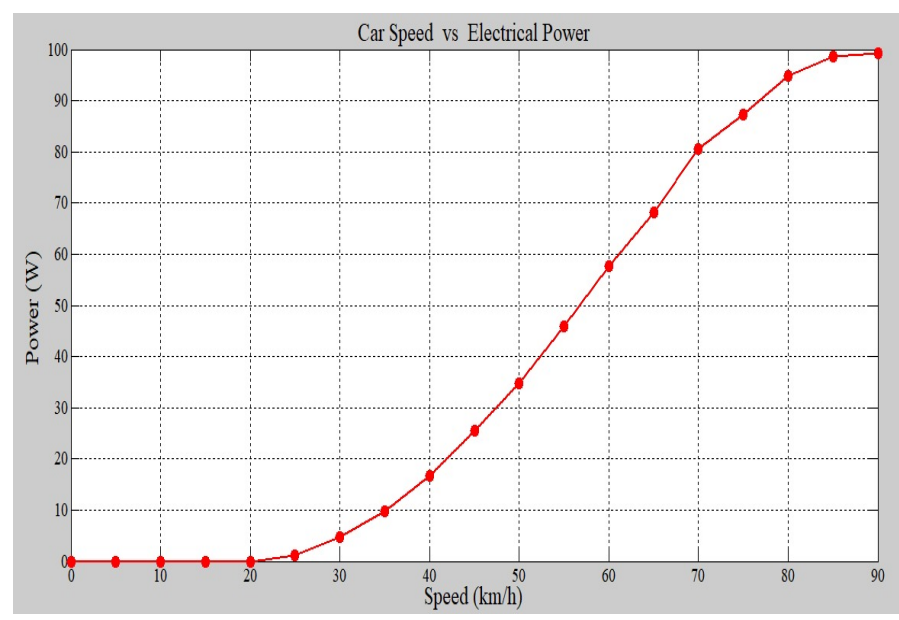

Figure 14. Electrical power output against different speeds.

\subsubsection{Time vs. Battery Charging Current}

The battery charging trend is presented with time in Figure 15. The chart shows the charging rate of the battery from $9 \mathrm{~V}$ (dead battery) up to the $13.1 \mathrm{~V}$ (fully charged) charging state of the battery. This is because of the battery resistance which varies. Thus, by this curve, it is to be estimated that when the battery is in a low charge condition, it has high resistance; and with the passage of time, as the battery starts charging and ionizing its charges, then the current increases with the decrease in the resistance. At one point, the maximum current drawn limit of the battery is achieved, and then the resistance of the battery increases again when it is becomes closer to the fully charged state.

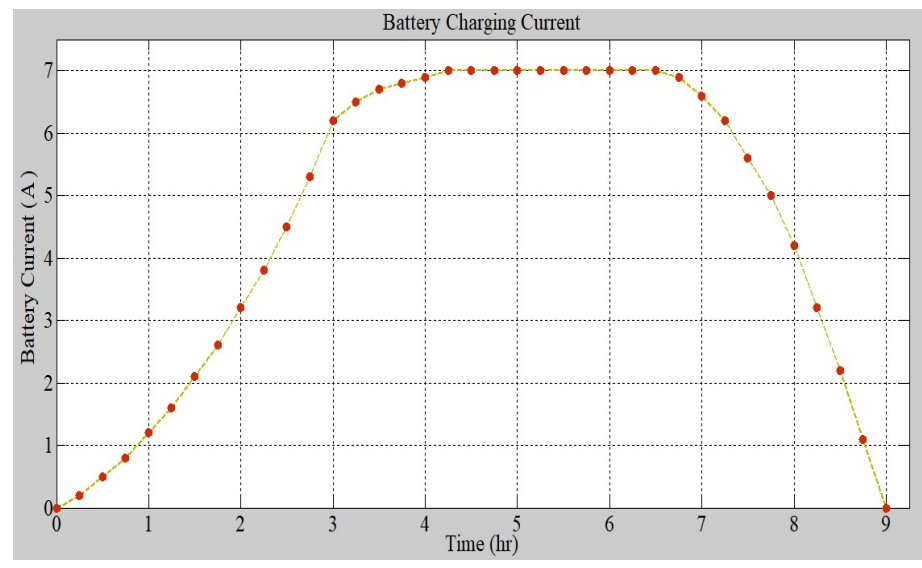

Figure 15. Battery charging trend with time.

\section{System Efficiency Analysis}

This system efficiency analysis was performed so as to depict the energy conversion efficiency from wind to electrical form via different transformations. First of all, the air strikes the car with mobility. As the moving car has some velocity, the air also strikes it with some velocity, but the air velocity is less than the speed of car. Thus, the car keeps on moving in the forward direction. This shows that the work being performed by the car is greater than the work performed by the wind on the car. In this research, an approach to harvest an amount of energy is proposed by utilizing the air pressure striking the car. This power can then become the turbine power after some losses. This power of the turbine is thus called because this is the energy caused by the wind turbine movement. Now, this rotating wind turbine has enough power to be used to do some useful work. Thus, this turbine is attached with a Permanent Magnet DC Motor, which has been used as a DC generator in this article, with the help of a mechanical shaft. This rotating wind turbine power will be transferred to the DC Motor and its rotor will start moving. It is important 
to note that the process also involves power losses during the transformation of energy from the wind turbine towards the motor.

The power available after all these transformations is the Mechanical Power which gives us an idea of how much work is being done by the generator (more specifically, by the rotor of the DC generator). As in this case, the work is being performed by the DC generator, as it will convert the mechanical power into electrical power. Electrical power is basically the measurement of the flow of current towards the load that is used for some purpose; in this case, it is a $12 \mathrm{~V}$ lead acid battery. This electrical power, as given below, is directed towards the battery after some adjustments and protections. First of all, the DC voltages are regulated at a desired DC voltage so as to charge the battery at a constant voltage. Then, this electrical power is supplied to the battery to be stored after using protection circuitry so that it can be utilized later to feed a source. Figure 16 and Table 1 exhibit system's efficiency at different stages of the harvesting process.

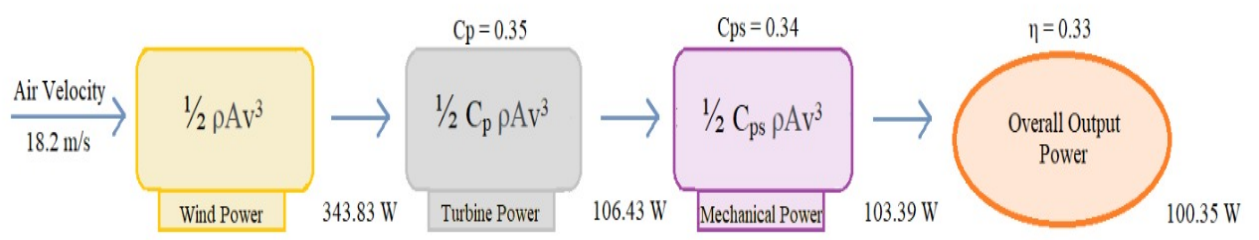

Figure 16. Efficiency of power generation at different stages.

Table 1. Power evaluation at different stages of the harvesting process.

\begin{tabular}{|c|c|c|c|c|c|}
\hline Car Speed $(\mathbf{k m} / \mathbf{h})$ & Air Velocity (m/s) & Wind Power (W) & $\begin{array}{c}\text { Turbine Power } \\
\text { (W) }\end{array}$ & $\begin{array}{l}\text { Mechanical Power } \\
\text { (W) }\end{array}$ & $\begin{array}{l}\text { Electrical Power } \\
\text { (W) }\end{array}$ \\
\hline 10 & 2.90 & 1.4 & 0.4 & 0.4 & 0.4 \\
\hline 20 & 4.30 & 4.6 & 1.4 & 1.3 & 1.3 \\
\hline 30 & 5.40 & 9.1 & 2.7 & 2.7 & 2.6 \\
\hline 40 & 7.70 & 26.4 & 8.0 & 7.8 & 7.5 \\
\hline 50 & 9.80 & 54.6 & 16.6 & 16.1 & 15.6 \\
\hline 60 & 13.3 & 133.5 & 41.5 & 40.3 & 39.1 \\
\hline 70 & 15.7 & 224.4 & 68.3 & 66.4 & 64.4 \\
\hline 80 & 18.2 & 343.8 & 106.4 & 103.4 & 100.3 \\
\hline 90 & 20.5 & 499.3 & 152.4 & 147.7 & 143.4 \\
\hline
\end{tabular}

\subsection{Betz Limit Analysis}

As per Betz's law [40], no turbine can capture more than 16/27 (59.3\%) of the kinetic energy in wind. The factor $16 / 27$ is known as Betz's coefficient. The Betz limit is based on an open-circle actuator. If a diffuser is utilized to gather extra wind stream and direct it through the turbine, more kinetic energy can be separated, however, the limit still applies to the cross-sectional area of the whole structure. According to the conducted analysis, the Betz limit efficiency is $30.3 \%$ for the turbine area of $0.0791 \mathrm{~m}$. For a motor of $350 \mathrm{~W}$ power, the overall system efficiency is $28.5 \%$. This could be improved by increasing the area of the diffuser, but keeping in mind that the Betz limit constraints are still sufficiently critical to influence the efficiency of the system.

\subsection{Drag Coefficient Analysis}

In a previous research work, which was based on the effect of a drag coefficient on the car in the presence of a charging device in various locations, the need for low or negligible drag force that would add up in the original drag force due to the charging system installation was emphasized. The results conclude that a harvesting system mounted on 
the front of a car bumper is a more suitable and promising point for maximum production and minimum drag compared to other positions of the car, as shown in Table 2.

Table 2. Drag coefficient at the different locations on a car.

\begin{tabular}{ccc}
\hline No. & Turbine Status & Drag Coefficient \\
\hline 1 & Without wind turbine & 0.39 \\
2 & At front of the car (bumper) & 0.39 \\
3 & At hood of the car (bonnet) & 0.45 \\
4 & At top of the car (roof) & 0.51 \\
\hline
\end{tabular}

\subsection{Power Generation Analysis}

According to the results gathered during analysis, the total power per hour was calculated to be approximately $100 \mathrm{~W}$, which is $28.5 \%$ efficient depending on the charging requirements of the battery. As per the motor configuration, the average power that can be produced by it is in between $15 \%$ and $35 \%$ of the total power. Keeping this information, it can be concluded that the power efficiency that was acquired is among the favorable requirements.

\subsection{Battery Discharge Time with respect to Car Loads}

As shown in Table 3, the more frequently used electrical loads of a car along with their power and current ratings are discussed and on this basis, the rightmost column was determined by driving. This column basically shows the time required to discharge a fully charged 40 Ah battery when each load is connected to it. These loads are of different types. The first one is the lighting loads which include the headlights, back lights, and the hazard lights. Secondly, body electrical loads include the power window and the wiper/washer system. The third type is media which includes video/audio systems, the navigation and GPS systems. Another type is the HVAC loads including the air compressor of the car.

The purpose of this analysis was to verify the capability of the proposed system to overrun the loads of a car on which it is installed. Considering the electricity generation, a statistical approach was used to estimate which loads of a car can be driven on a fully charged 40 Ah battery-charged using the proposed system. Moreover, if each of them is connected to the battery, how much time will be required to use the battery completely? The answer to this is in the rightmost column. Afterwards, a very important analysis was performed. If all the loads excluding the air compressor were left to run on the battery with the specifications mentioned above, then it would keep them running all these loads for approximately half an hour, i.e., $0.52 \mathrm{~h}$ (31 $\mathrm{min})$. However, if the air compressor was included in the loads being driven over the battery, it can still keep all these loads running for approximately $0.34 \mathrm{~h}$, i.e., $20 \mathrm{~min}$.

It is also pertinent to see whether a proposed system is capable of supporting the loads mentioned in Table 3. We covered all these loads one by one to understand each of them. The back lights and the hazard lights are those which could directly be supported by the proposed architecture while leaving some surplus energy. The headlights, power windows, and wiper washer system are the loads that could be supported with the full generated power being utilized, i.e., without leaving any extra energy. As far as the air compressor, the navigation and GPS systems are concerned, the harvested energy is not ample enough to support them with a direct supply. They will require an additional external electric supply as well. Moreover, the available power would be $20 \%$ and $40 \%$ of the power ratings of the air compressor and navigation/GPS system, respectively. This will help reduce their dependency on the battery or grid power. Hence, it can be concluded that the proposed system generates an ample amount of energy to directly support the frequently used loads of a car, i.e., without needing to employ a battery. 
Table 3. Battery discharge time with respect to loads.

\begin{tabular}{|c|c|c|c|c|}
\hline Serial No. & Loads & Power (W) & Current (A) & Discharge Time (h) \\
\hline 1 & Headlights (2) & 120 & 10 & 4.0 \\
\hline 2 & Backlights (2) & 50 & 4.1 & 9.1 \\
\hline 3 & Hazard lights (4) & 84 & 7.0 & 5.7 \\
\hline 4 & Power window (4) & 120 & 10 & 4.0 \\
\hline 5 & Wiper and washer & 140 & 9.8 & 4.0 \\
\hline 6 & Video and audio system & 250 & 20.8 & 1.9 \\
\hline \multirow[t]{2}{*}{7} & Navigation and GPS & 150 & 12.5 & 3.2 \\
\hline & Sub. Total & 914 & 76.1 & 0.52 \\
\hline \multirow[t]{2}{*}{8} & Air compressor & 500 & 41.6 & 0.9 \\
\hline & Total & 1414 & 117.8 & 0.34 \\
\hline
\end{tabular}

\subsection{Design and Cost Analysis}

As a major objective of our research, the positioning of the fan was a vital aspect of our analysis. The experimental results have shown a considerably better performance than the procedures used in previous papers. This proves our theory that the front position is the perfect spot for the adjustment of the wind turbine system for maximum utility. The fan used for wind generation worked satisfactorily with the given motor and circuit parameters. As a whole, the complete study including the hardware material for practical analysis was very cost-effective. All the materials required for the testbed work were available in the local market and were cheap to buy, while also ensuring their precision and durability. As a team, it is our strong belief that in the future, if an industrial version is created, the end product will be very user friendly in terms of cost.

\section{Conclusions}

With the surge to explore new dimensions in mitigating carbon emissions, today's smart cities are committed to increase their low emission zones in an effort to replace the conventional gas vehicles with electric vehicles, effectively meeting the requirements of several IoV use cases. To support the optimal operation, the design of a wind power harvester was proposed and evaluated in this article. The aerodynamic drag and air speed qualities around the vehicle with a wind turbine framework were numerically researched. The vehicle model was simulated by a Fluent module of ANSYS software to contemplate the wind stream trademark around the vehicle body and decide the drag power of the vehicle at a specific speed. Furthermore, on the basis of the obtained results, practical evaluation analysis was also performed in order to achieve the research objectives. After the simulated and practical experiments, the front bumper is recommended to be an ideal spot on the car for installing this kind of device for making an effective charging system of EVs. This article emphasized the charging of the EVs while utilizing their batteries considering a speed range from 40 to $90 \mathrm{~km} / \mathrm{h}$. This range can be improved by designing a DC voltage regulator capable of taking a larger range of input voltages to be stabilized. The authors are committed to extend this work towards automating the energy generation process inducing the integrated control and regulation of the generated voltage, along with exploring different options to transfer surplus power to the national grid for general purpose utilization.

Author Contributions: Conceptualization, Z.A.K., H.H.R.S., and M.A.; methodology, Z.A.K., H.H.R.S. and M.A.; validation, I.U.R., M.A.I. and P.C.; formal analysis, H.H.R.S.; resources, I.U.R., P.C.; writing-original draft preparation, Z.A.K., H.H.R.S. and M.A.; writing—review and editing, Z.A.K., M.A.I., H.H.R.S., P.C.; project administration, M.A.I., H.H.R.S., and P.C.; funding acquisition, M.A.I. and H.H.R.S. All authors have read and agreed to the published version of the manuscript.

Funding: This research was partly funded by EPSRC Global Challenges Research Fund-the DARE project-EP/P028764/1. 
Institutional Review Board Statement: Not applicable.

Informed Consent Statement: Not applicable.

Data Availability Statement: Not applicable.

Conflicts of Interest: The authors declare no conflict of interest.

\section{References}

1. Raja, G.; Anbalagan, S.; Vijayaraghavan, G.; Dhanasekaran, P.; Al-Otaibi, Y.D.; Bashir, A.K. Energy-Efficient End-to-End Security for Software Defined Vehicular Networks. IEEE Trans. Ind. Inform. 2020, 17, 5730-5737. [CrossRef]

2. Hussain, S.A.; Iqbal, M.; Saeed, A.; Raza, I.; Raza, H.; Ali, A.; Bashir, A.K.; Baig, A. An efficient channel access scheme for vehicular ad hoc networks. Mob. Inf. Syst. 2017, 2017. [CrossRef]

3. Sherazi, H.H.R.; Raza, I.; Chaudary, M.H.; Hussain, S.A.; Raza, M.H. Multi-radio over fiber architecture for road vehicle communication in VANETs. Procedia Comput. Sci. 2014, 32, 1022-1029. [CrossRef]

4. Iwendi, C.; Uddin, M.; Ansere, J.A.; Nkurunziza, P.; Anajemba, J.H.; Bashir, A.K. On detection of Sybil attack in large-scale VANETs using spider-monkey technique. IEEE Access 2018, 6, 47258-47267. [CrossRef]

5. Azzaoui, N.; Korichi, A.; Brik, B.; el amine Fekair, M.; Kerrache, C.A. On the Communication Strategies in Heterogeneous Internet of Vehicles. In Proceedings of the Third International Conference on Smart City Applications, Casablanca, Morocco, 2-4 October 2019; Springer: Cham, Switzerland, 2019; pp. 783-795.

6. Sherazi, H.H.R.; Khan, Z.A.; Iqbal, R.; Rizwan, S.; Imran, M.A.; Awan, K. A heterogeneous IoV architecture for data forwarding in vehicle to infrastructure communication. Mob. Inf. Syst. 2019, 2019, 3101276. [CrossRef]

7. Kumar, A.; Hariharan, N. Enhanced Mobility Based Content Centric Routing In RPL for Low Power Lossy Networks in Internet of Vehicles. In Proceedings of the 2020 3rd International Conference on Intelligent Autonomous Systems (ICoIAS), Singapore, 26-29 February 2020; pp. 88-92.

8. Sherazi, H.H.R.; Imran, M.A.; Boggia, G.; Grieco, L.A. Energy harvesting in LoRaWAN: A cost analysis for the industry 4.0. IEEE Commun. Lett. 2018, 22, 2358-2361. [CrossRef]

9. Sherazi, H.H.R.; Grieco, L.A.; Imran, M.A.; Boggia, G. Energy-Efficient LoRaWAN for Industry 4.0 Applications. IEEE Trans. Ind. Inform. 2021, 17, 891-902. [CrossRef]

10. Raja, G.; Dhanasekaran, P.; Anbalagan, S.; Ganapathisubramaniyan, A.; Bashir, A.K. SDN-enabled Traffic Alert System for IoV in Smart Cities. In Proceedings of the IEEE INFOCOM 2020-IEEE Conference on Computer Communications Workshops (INFOCOM WKSHPS), Toronto, ON, Canada, 6-9 July 2020; pp. 1093-1098.

11. Citroni, R.; Di Paolo, F.; Livreri, P. Evaluation of an optical energy harvester for SHM application. AEU Int. J. Electron. Commun. 2019, 111, 152918. [CrossRef]

12. Citroni, R.; Di Paolo, F.; Livreri, P. A novel energy harvester for powering small UAVs: Performance analysis, model validation and flight results. Sensors 2019, 19, 1771. [CrossRef]

13. Sun, D.; Ou, Q.; Yao, X.; Gao, S.; Wang, Z.; Ma, W.; Li, W. Integrated human-machine intelligence for EV charging prediction in 5G smart grid. EURASIP J. Wirel. Commun. Netw. 2020, 2020, 139. [CrossRef]

14. Karfopoulos, E.L.; Hatziargyriou, N.D. A multi-agent system for controlled charging of a large population of electric vehicles. IEEE Trans. Power Syst. 2012, 28, 1196-1204. [CrossRef]

15. Xie, D.; Chu, H.; Lu, Y.; Gu, C.; Li, F.; Zhang, Y. The concept of EV's intelligent integrated station and its energy flow. Energies 2015, 8, 4188-4215. [CrossRef]

16. Quartey, G.; Adzimah, S.K. Generation of electrical power by a wind turbine for charging moving electric cars. J. Energy Technol. Policy 2014, 4, 19.

17. Ohya, Y.; Karasudani, T. A shrouded wind turbine generating high output power with wind-lens technology. Energies 2010, 3, 634-649. [CrossRef]

18. Sofian, M.; Nurhayati, R.; Rexca, A.; Syariful, S.S.; Aslam, A. An evaluation of drag coefficient of wind turbine system installed on moving car. Appl. Mech. Mater. 2014, 660, 689-693. [CrossRef]

19. Bijlani, B.; Rathod, P.P.; Sorthiya, A.S. Experimental and Computational Drag Analysis of Sedan and Square-Back Car. Int. J. Adv. Eng. Technol. 2013, 4, 63-65.

20. Awal, M.R.; Jusoh, M.; Sakib, M.N.; Hossain, F.S.; Beson, M.R.C.; Aljunid, S.A. Design and implementation of vehicle mounted wind turbine. ARPN J. Eng. Appl. Sci. 2015, 10, 8699-8860.

21. Zakaria, M.Y.; Pereira, D.A.; Hajj, M.R. Experimental investigation and performance modeling of centimeter-scale micro-wind turbine energy harvesters. J. Wind Eng. Ind. Aerodyn. 2015, 147, 58-65. [CrossRef]

22. Karthikeyan, N.; Murugavel, K.K.; Kumar, S.A.; Rajakumar, S. Review of aerodynamic developments on small horizontal axis wind turbine blade. Renew. Sustain. Energy Rev. 2015, 42, 801-822. [CrossRef]

23. Kishore, R.A.; Priya, S. Design and experimental verification of a high efficiency small wind energy portable turbine (SWEPT). $J$. Wind Eng. Ind. Aerodyn. 2013, 118, 12-19. [CrossRef]

24. Zhao, Z.; Wang, T.; Zhang, B.; Shi, J. Energy harvesting from vehicle suspension system by Piezoelectric harvester. Math. Probl. Eng. 2019, 2019, 1086983. [CrossRef]

25. Xie, X.; Wang, Q. Energy harvesting from a vehicle suspension system. Energy 2015, 86, 385-392. [CrossRef] 
26. Xie, X.; Wang, Q. A mathematical model for piezoelectric ring energy harvesting technology from vehicle tires. Int. J. Eng. Sci. 2015, 94, 113-127. [CrossRef]

27. Lee, J.; Chun, Y.; Kim, J.; Park, B. An Energy-Harvesting System Using MPPT at Shock Absorber for Electric Vehicles. Energies 2021, 14, 2552. [CrossRef]

28. Wai, C.K.; Rong, Y.Y. Electric vehicle energy harvesting system regenerative shock absorber for electric vehicle. In Proceedings of the 2013 IEEE Conference on Sustainable Utilization and Development in Engineering and Technology (CSUDET), Selangor, Malaysia, 30 May-1 June 2013; pp. 7-10.

29. Bezanilla, F. The voltage sensor in voltage-dependent ion channels. Physiol. Rev. 2000, 80, 555-592. [CrossRef]

30. Singh, S.; Bhullar, S. Hardware implementation of auto switching and light intensity control of LED lamps. Balk. J. Electr. Comput. Eng. 2016, 4, 67-71. [CrossRef]

31. Vobecky, J.; Hazdra, P.; Homola, J. Optimization of power diode characteristics by means of ion irradiation. IEEE Trans. Electron. Dev. 1996, 43, 2283-2289. [CrossRef]

32. Gunn, C.N.; Harding, S.J.; Ricci, M.A.; Loewen, D.N.; Cowan, P.C.; Hancock, M.A. Current Sensor Assembly. U.S. Patent 7,557,563, 7 July 2009.

33. Babir, M.R.N.; Al Mahmud, S.A.; Mostary, T. Efficient M-QAM Digital Radio over Fiber System for Vehicular ad hoc Network. In Proceedings of the 2019 International Conference on Robotics, Electrical and Signal Processing Techniques (ICREST), Dhaka, Bangladesh, 10-12 January 2019; pp. 34-38.

34. Munshi, A.; Unnikrishnan, S. Vehicle to Vehicle Communication Using DS-CDMA Radar. Procedia Comput. Sci. 2015, 49, 235-243. [CrossRef]

35. Manyonge, A.W.; Ochieng, R.; Onyango, F.; Shichikha, J. Mathematical modelling of wind turbine in a wind energy conversion system: Power coefficient analysis. Appl. Math. Sci. 2012, 6, 4527-4536.

36. Ochieng, R.; Ochieng, R. Analysis of the betz criterion in wind turbine power modelling by use of "variational principle (method)" in the power equation. Int. J. Energy, Environ. Econ. 2015, 23, 283.

37. Castelli, M.R.; De Betta, S.; Benini, E. Effect of blade number on a straight-bladed vertical-axis Darreius wind turbine. World Acad. Sci. Eng. Technol. 2012, 61, 305-3011.

38. Hegde, S.S.; Thamban, A.; Bhai, S.P.M.; Ahmed, A.; Upadhyay, M.; Joishy, A.; Mahalingam, A. Highway mounted horizontal axial flow turbines for wind energy harvesting from cruising vehicles. In Proceedings of the ASME International Mechanical Engineering Congress and Exposition, Phoenix, AZ, USA, 11-17 November 2016.

39. Fotso, B.M.; Nguefack, C.F.; Talawo, R.C.; Fogue, M. Aerodynamic analysis of an electric vehicle equipped with horizontal axis savonius wind turbines. Int. J. Recent Trends Eng. Res. IJRTER 2019, 5, 17-26.

40. Gorban', A.N.; Gorlov, A.M.; Silantyev, V.M. Limits of the turbine efficiency for free fluid flow. J. Energy Resour. Technol. 2001, 123, 311-317. [CrossRef] 